\title{
Fen bilgisi öğretmen adaylarının materyal geliştirme konusundaki teknolojik pedagojik alan bilgisi (TPAB) öz-yeterlik ölçeği: geliştirme, güvenirlik ve geçerlik çalışması
}

\author{
Muhammed Doğukan Balçın
}

Manisa Celal Bayar Üniversitesi, Fen Bilimleri Enstitüsü, Manisa, Türkiye, dogukanbalcin@gmail.com

\author{
Ayşegül Ergün
}

Manisa Celal Bayar Üniversitesi, Eğitim Fakültesi, Manisa, Türkiye, ergunaysegul@ gmail.com

ÖZ $\mathrm{Bu}$ araştırmanın amacı, fen bilgisi öğretmen adaylarının materyal geliştirme konusundaki teknolojik pedagojik alan bilgisi (TPAB) öz-yeterliklerini belirleyen geçerli ve güvenilir bir ölçek geliştirilmesidir. Araştırmada nicel bir araştırma yöntemi olan tarama modeli kullanılmıştır. Araştırma 2015-2016 eğitimöğretim yılı güz döneminde, Türkiye'nin 12 farklı üniversitesinin üçüncü ve dördüncü sınıfında öğrenim görmekte olan 659 fen bilgisi öğretmen adayı ele alınarak gerçekleştirilmiştir. Araştırmada kullanılmak üzere geliştirilecek ölçeğin maddelerini belirlemek amacı ile literatür taraması yapılmıştır. Ayrıca çalışma grubunda olmayan fen bilgisi öğretmen adayları, fen bilgisi eğitimi alanında lisansüstü eğitim görmekte olan bireyler ve TPAB alanında çalışmış olan araştırmacılar ile görüşmeler yapılmıştır. Ölçeğin kapsam ve görünüş geçerliği için uzman görüşüne başvurulmuştur. Ölçümlerden yapılan yorumların yapı geçerliği için ise Açımlayıcı Faktör Analizi (AFA) ve Doğrulayıcı Faktör Analizi (DFA) uygulanmıştır. AFA sonucunda toplam varyansın \%46.37'sini açıklayan, 40 madde ve sekiz faktörden oluşan bir yapı elde edilmiştir. Ölçeğe ait cronbach alpha iç tutarlılık katsayısı 0.93 olarak hesaplanmıştır. Araştırma sonucunda fen bilgisi öğretmen adaylarının materyal geliştirme konusundaki TPAB öz-yeterliklerini belirleyen geçerli ve güvenilir bir ölçme aracı oluşturulmuştur.

Anahtar

Kelimeler Teknolojik Pedagojik Alan Bilgisi (TPAB), öz-yeterlik, materyal gelişstirme, fen bilimleri

\section{Technological pedagogical content knowledge (TPCK) self-efficacy scale for pre-service science teachers on material development: development, reliability and validity study}

\footnotetext{
ABSTRACT The purpose of this study is to develop a valid and reliable scale to determine the Technological Pedagogical Content Knowledge (TPCK) Self-Efficacy on material development for pre-service science teachers. In the study, survey model, which is a quantitative research method, was used. The study was conducted in the academic year of 2015-2016 and 659 pre-service science teachers attending third and fourth classes of colleges in 12 different universities Turkey participated. Literature was reviewed for the purpose of determining the items of scale to be used in research. Also, interviews were made with preservice science teachers, postgraduate students in science and researchers worked in the TPCK. Expert opinions were taken for the scope and face validity of the scale. As for the structure validity of the comments made from the measurement, exploratory factor analysis (EFA) and confirmatory factor analysis (CFA) were applied. As a result of EFA, a structure consisting of 40 items and eight factors which explains $46.37 \%$ of the total variance. Cronbach alpha internal consistency coefficient of the scale was calculated as 0,93. At the end of the study, a valid and reliable tool which determines Self-Efficacy Scale for Pre-service Science Teachers on Material Development was developed.

Keywords Technological Pedagogical Content Knowledge (TPCK), self-efficacy, material development, science
} 


\section{EXTENDED SUMMARY}

Competencies required for teachers to meet their professional careers are provided through their undergraduate education. These competencies are competencies related to subject content, competencies related to teaching-learning process, competencies related to monitoring, evaluating and recording the learning and complementary professional competencies (YÖK, 2008).

Content knowledge $(\mathrm{CK})$ represents all the information regarding the subjects on the lesson content to be taught. Pedagogical Knowledge (PK) can be qualified as competencies related to teaching-learning process, competencies related to monitoring, evaluating and recording the learning and complementary professional competencies. Content Knowledge (CK) and Pedagogical Knowledge (PK) were combined by Shulman (1986) and the concept of Pedagogical Content Knowledge (PCK) was formed. A teacher with PCK should have the competence of designing and implementing the subjects to be taught.

The knowledge that technology provides to the society makes it well-supported and stronger for the future. Therefore, training individuals who can use technology in all aspects of life became an inevitable exigence. Integration of technology is an integral part of a good education.

The technological tools use knowledge of a teacher in teaching process effectively is constituted under technological knowledge (Ugurlu, 2009). For the teaching technologies to be used effectively in their lessons, teachers should have a command of PK and CK they have and this knowledge should be effectively integrated with TK. The concept of Technological Pedagogical Content Knowledge (TPCK) was created by Mishra and Koehler (2006)by adding the technology dimension onto the concept of Pedagogical Content Knowledge (PCK) created by Shulman (1986). Technological Pedagogical Content Knowledge (TPCK) is shown as a way for teachers and teacher candidates to effectively integrate technology to learning-teaching process.

When the curriculums of science courses are analyzed, it can be seen that science and technology are interconnected with each other. As the grades of students increase, the subjects in science lessons with abstract concepts also increase. In order to concretize abstract concepts and make the subjects easier to teach, materials are more preferred that the students can touch, hear and see. Technological Pedagogical Content Knowledge (TPCK) is important for pre-service teachers with respect to create effective teaching materials.

There is no scale in the literature that determines the Technological Pedagogical Content Knowledge (TPCK) self-efficacy of pre-service science teachers. The fulfillment of this need in the literature was aimed in the study.

The study was conducted with 659 pre-service science teachers studying in 12 different universities around Turkey, in 2015-2016 educational fall period. A literature search was made for the purpose of determining the items of scale to be developed for use in research. Also, interviews were made with science teacher candidates not participating in the study, individuals studying in the postgraduate in science and researchers worked in the Technological Pedagogical Content Knowledge (TPCK) field. Expert opinions were taken for the scope and face validity of the scale. As for the structure validity of the comments made from the measurement, exploratory factor analysis (EFA) and confirmatory factor analysis (CFA) were applied. As a result of EFA, a structure consisting of 40 items and eight factors which explains $46.37 \%$ of the total variance. These factors revealed were named as TPCK, TK, CK on basic and sub-specialties of science, PK, CK, PCK, TCK, TPK. At the end of the study, a valid and reliable tool determining the TPCK self-efficacy scale of pre-service science teachers on material design was developed. 


\section{GíRiș}

Öğretmenlerin meslek hayatına geçişi sırasında sahip olması gereken yeterlikler lisans eğitimi boyunca öğretmen adaylarına verilmektedir. Yükseköğretim Kurulu (YÖK)'ün "Milli Eğitimi Geliştirme Projesi" kapsamında, MEB ve YÖK tarafindan öğretmenlerin sahip olması gereken bu yeterlikler "öğretmen yeterlik listesi”nde belirlenmiş olup dört ana başlık altında toplanmıştır (Yüksek Öğretim Kurumu [YÖK], 2008). Bunlar:

1. Konu alanı ve alan eğitimine ilişkin yeterlikler

2. Öğretme-öğrenme sürecine ilişkin yeterlikler

3. Öğrencilerin öğrenmelerini izleme, değerlendirme ve kayıt tutma ile ilgili yeterlikler,

4. Tamamlayıcı mesleki yeterliklerdir (YÖK, 2008).

"Konu alanı ve alan eğitimi kapsamında öğretmenin yeterlikleri arasında konu alanını, kavram ve becerileri anlama, alan bilgisini gerektiği biçimde kullanma ve artırabilme, alan ile ilgili öğretim programını bilme, özel öğretim yöntemlerini ve öğretim teknolojilerini bilme, konu alanı ile ilgili bilgi teknolojilerini bilme" yer almaktadır (YÖK, 2008). Bu kapsam içerisindeki alan bilgisi (AB), ders alanında mevcut olan ve ögretilecek olan derse ait konularla ilgili tüm bilgileri ifade etmektedir. Öğretme-öğrenme sürecine ilişkin alt yeterliklerde ise planlama, öğretim süreci, sınıf yönetimi, kayıt tutma ve değerlendirme gibi beceriler yer almaktadır.

"Öğretme-öğrenme sürecine ilişkin yeterlikler, öğrencilerin öğrenmelerini izleme, değerlendirme ve kayıt tutma ile ilgili yeterlikler ile tamamlayıcı mesleki yeterlikler" öğretmenin sahip olduğu pedagojik bilgi (PB) olarak nitelendirilebilir. İyi bir öğretmenin konu alan bilgisi ile birlikte, sahip olduğu alan bilgisini öğrencilerine nasıl kazandıracağını da bilmesi gerekmektedir (Canbazoğlu, 2008; Canbazoğlu, Demirelli, ve Kavak, 2010; Dede, Bayazit, ve Soybaş, 2010; Canbazoğlu-Bilici, 2012). Shulman (1986) tarafından da bu iki bilgi türü birleştirilmiş olup Pedagojik Alan Bilgisi (PAB) kavramı oluşturulmuştur. PAB kavramı, öğretim sürecinde öğretmenin konu hakkında sahip olduğu alan bilgisinin ötesinde, öğretmenin içerik bilgisini öğretme biçimi olarak ifade edilmektedir (Gömleksiz ve Fidan, 2011). PAB'a sahip olan bir öğretmen konuların öğretimini nasıl gerçekleştireceği ve ne şekilde uygulayacağ konusunda yeterliliğe sahiptir (Akyüz, Pektaş, Kurnaz, ve Kabataş-Memiş, 2014).

PAB kavramı, öğretim sürecinde öğretmenin konu hakkında sahip olduğu alan bilgisinin ötesinde, öğretmenin içerik bilgisini öğretme biçimi olarak ifade edilmektedir (Gömleksiz ve Fidan, 2011). PAB'a sahip olan bir öğretmen konuların öğretimini nasıl gerçekleştireceği ve ne şekilde uygulayacağ konusunda yeterliliğe sahiptir (Akyüz, Pektaş, Kurnaz ve Kabataş-Memiş, 2014).

\section{Teknolojik Pedagojik Alan Bilgisi (TPAB)}

Günümüzde eğitim - öğretim sürecinde kalem, kağıt gibi geleneksel teknolojinin yanında, ilerleyen teknoloji ile eğitim alanımıza projeksiyon, akıllı tahta gibi dijital teknolojiler girmiştir. Teknoloji, bilgi toplumunun kaynağı olan insanı daha donanımlı hale getirir ve bireyin teknolojik bilgiye sahip olmasını sağlar. Bu bağlamda teknolojiyi üretebilen ve hayatın bütün alanlarında kullanabilen bireyler yetiştirme gerekliliği ortaya çıkmıştır. Bu gerekliliğin oluştuğu alanlardan biri de eğitim alanıdır.

Eğitim kurumlarında teknolojiyi kullanabilen bireyler yetiştirmenin önemi her geçen gün artmaktadır. Öğretmenler de öğrencilere alan bilgilerini sahip oldukları pedagojik alan bilgisiyle aktarırken daha verimli olabilmek açısından teknolojik bilgi (TB) yi kullanmaktadır. Teknoloji entegrasyonu iyi bir öğretimin ayrılmaz parçası olarak görülmesine (Pierson, 1999) rağmen günümüzde, öğretmenlerin konu alan bilgileri ile ilişkili olan teknolojik bilgilerini ve teknolojiyi öğretim sürecinde kullanabilme becerilerini geliştirmeleri gerekmektedir (Demir ve Bozkurt, 2011; Niess, 2005; Niess, 2011). Eğitim teknolojilerinin öğretime entegrasyonu sürecinde etkili kullanılabilmesi için öğretmenlerin sahip olduğu Pedagojik Bilgi (PB) ve Alan Bilgisi (AB) konularına da hâkim olunması ve bu bilgilerin Teknolojik Bilgi (TB) ile etkili bir şekilde bütünleştirilmesi gerekmektedir. Öğretmenlerin, teknolojinin ilerlemesi ve eğitime entegre edilmesiyle teknoloji ve pedagojiyi birleştirmesi üzerine yeni bir kuramsal çerçeve oluşturulmuştur. Shulman (1986)'ın oluşturduğu Pedagojik Alan Bilgisi (PAB) kavramına Mishra ve Koehler (2006)'in teknoloji boyutunu eklemesiyle Teknolojik Pedagojik Alan Bilgisi (TPAB) kavramı ortaya çıkmıştır.

Teknoloji, bilgi toplumunun kaynağı olan insanı daha donanımlı hale getirir ve bireyin teknolojik bilgiye sahip olmasını sağlar. Bu bağlamda teknolojiyi üretebilen ve hayatın bütün alanlarında kullanabilen bireyler yetiştirme gerekliliği ortaya çıkmıştır. Bu gerekliliğin oluştuğu alanlardan biri de eğitim 
alanıdır. Eğitim kurumlarında teknolojiyi kullanabilen bireyler yetiştirmenin önemi her geçen gün artmaktadır. Öğretmenler, öğrencilere alan bilgilerini sahip oldukları pedagojik alan bilgisiyle aktarırken daha verimli olabilmek açısından teknolojik bilgi (TB)'yi kullanmaktadır. Öğretmenlerin teknolojiyi öğrenme-öğretme sürecine katabilmeleri, teknolojiyi kullanabilme yeterliliğine sahip bireyler yetiştirme açısından önemli görülmektedir. TB kalem ve kâğıt gibi geleneksel teknolojiler ile animasyon, akıllı tahta gibi çağdaş teknolojiler hakkındaki çeşitli bilgiyi içermektedir. Benzer şekilde bir öğretmenin teknolojik araçların nasıl kullanıldığını bilmesi, bu teknolojik araçların öğretim sürecinde nasıl etkili kullanılabileceğini bilmesi teknolojik bilgi kapsamında yer almaktadır (Uğurlu, 2009).

Eğitim teknolojilerinin ortaya çıkmasıyla, kazandırılmak istenen teknolojik beceriler, içerik bilgisinden ve pedagojik bilgiden ayrı tutulmuştur (Hargvare ve Hsu, 2000; Graham, Culatta, Pratt, \& West, 2004). Teknolojik becerinin pedagojik bilgi ve alan bilgisinden bağımsız olarak kazandırılamayacağının farkına varılmasıyla, bir uyum süreci gerçekleşerek teknolojinin öğrenme-öğretme sürecine entegre edilmesine odaklanılmıştır (Burgoyne, Cantrell, Smith, \& Harris, 2009). Teknoloji entegrasyonu iyi bir öğretimin ayrılmaz parçası olarak görülmesine (Pierson, 1999) rağmen günümüzde, öğretmenlerin konu alan bilgileri ile ilişkili olan teknolojik bilgilerini ve teknolojiyi öğretim sürecinde kullanabilme becerilerini geliştirmeleri gerekmektedir (Demir ve Bozkurt, 2011; Niess, 2005; Niess, 2011).

YÖK'ün belirlemiş olduğu öğretmen yeterlikleri nitelikli ve istendik bireyler yetiştirmemizde önemli bir ölçüttür. Öğretmenlerin sahip olması gereken yeterlikler hayatımıza teknolojinin girmesiyle farklı bir boyut kazanmıştır. Eğitim teknolojilerinin öğretime entegrasyonu sürecinde etkili kullanılabilmesi için öğretmenlerin sahip olduğu pedagojik bilgi ve alan bilgisi konularına da hâkim olunması ve bu bilgilerin Teknolojik bilgi ile etkili bir şekilde bütünleştirilmesi gerekmektedir. Öğretmenlerin, teknolojinin ilerlemesi ve eğitime uyum sürecinde, teknoloji ve pedagojiyi birleştirmesi üzerine yeni bir kuramsal çerçeve oluşturulmuştur. Shulman (1986)'ın oluşturduğu Pedagojik Alan Bilgisi (PAB) kavramına Mishra ve Koehler (2006)'in teknoloji boyutunu eklemesiyle Teknolojik Pedagojik Alan Bilgisi (TPAB) kavramı ortaya çıkmıştır.

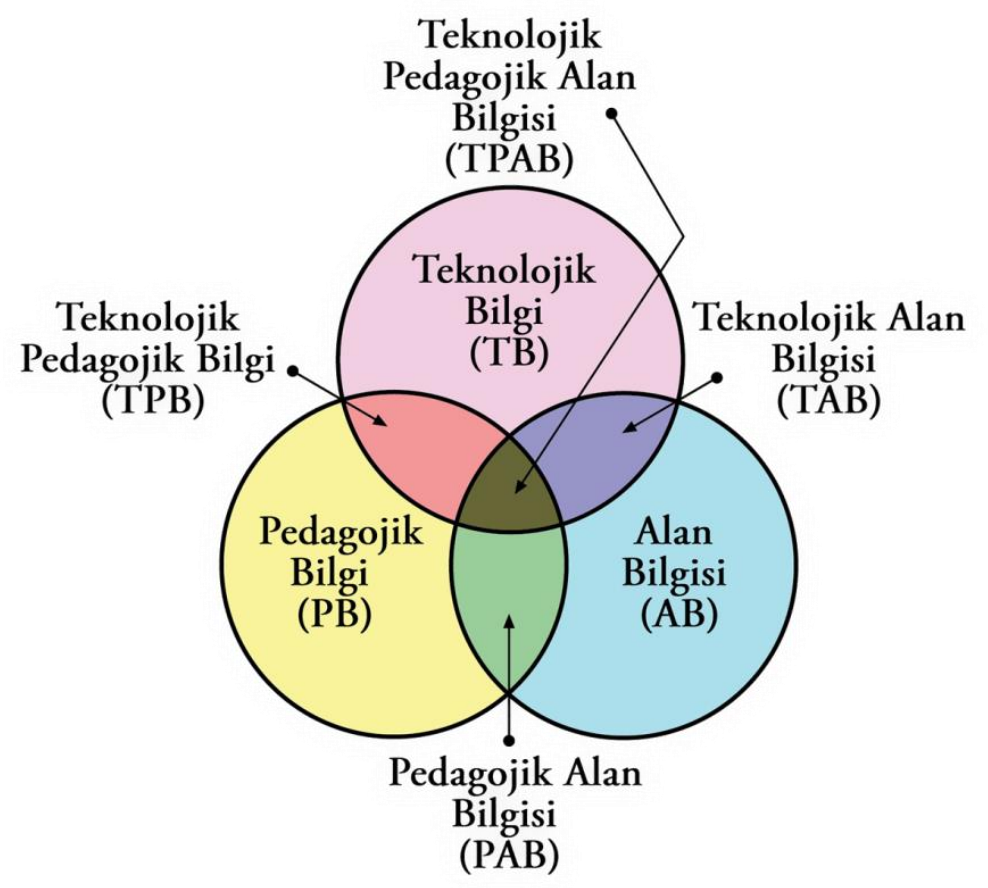

Şekil 1. Teknolojik Pedagojik Alan Bilgisi (TPAB) Kuramsal Çerçevesi, Mishra ve Koehler (2006)

TPAB kuramsal çerçevesi incelendiğinde temel üç farklı bilgi alanı ortaya çıkmaktadır (Harris, Mishra, \& Koehler 2007). Bu temel bilgi alanları Alan Bilgisi (AB), Pedagoji Bilgisi (PB) ve Teknoloji Bilgisi (TB) dir. Üç temel bilgi alanının kesişimi ile Pedagojik Alan Bilgisi (PAB), Teknolojik Pedagojik Bilgisi (TPB) ve Teknolojik Alan Bilgisi (TAB) temel kavramları ortaya çıkmaktadır. Şekil 1 de belirtildiği gibi üç temel kavramının birleşimiyle de Teknolojik Pedagojik Alan Bilgisi (TPAB) kavramı ortaya çıkmıştır. $\mathrm{Bu}$ bağlamda TPAB bu üç bilgi türünü bütünleştirmiş olup aynı zamanda bu bilgi 
türlerinin etkileşim içerisinde olduğu görülmektedir (Mishra ve Koehler, 2006; Koehler, Mishra, ve Yahya, 2007; Schmidt, Baran, Thompson, Mishra, Koehler, ve Shin, 2009).

$\mathrm{TPAB}$, öğretmen ve öğretmen adaylarının teknolojiyi öğrenme-öğretme sürecine ve bu ortamlara en iyi şekilde uyum sağlanmasının bir yolu olarak gösterilmektedir (Mishra ve Koehler, 2006). Türk Eğitim Derneği [TED] (2009)'nin yapmış olduğu “öğretmenlik mesleği genel yeterlikleri” konulu araştırmada başarılı bir öğretmende bulunması gereken yeterlikler arasında TPAB açıkça belirtilmiş ve bu raporda TPAB “Öğretim programları ve konu alanı, programın nasıl öğretileceği ve alanın diğer alanlarla ilişkisi, alandaki son gelişmeler, alanın temel kavram, araç ve yapıları, öğretilecek içeriğin teknoloji ile bütünleştirilmesi hakkında bilgili olma" şeklinde tanımlanmış, bu yeterliğe hem öğretmen adaylarının hem de hizmetteki öğretmenlerin sahip olması gerektiği belirtilmiştir. Günümüzün sosyo-kültürel ve teknolojik gelişmeleri yaşam şeklimizi önemli ölçüde değiştirmiştir. Hızla değişen sosyo-kültürel ve teknolojik gelişmeler gelecekte de hayatımızı etkileyecek ve eğitim alanına yansıması da devam edecektir.

Fen ve teknolojinin iç içe olduğu ve fen, teknoloji ile zenginleştirilmeye yatkın olduğundan 2004 yılında öğretim programı revizyonunda fen bilgisi dersinin adı fen ve teknoloji olarak değiştirilmiş̧tir. Fen ve teknolojinin birçok ortak noktası olduğu görülmektedir. Hem bilimsel araştırmalarda hem de teknolojiyi tasarlama süreçlerinde benzer beceriler ve bilişsel alışkanlıklar kullanılır. Fen ve teknoloji bir bütün olsa da birbirinden ayıran amaçları bulunmaktadır. Fenin amacı "doğal dünyayı anlayarak açıklamaya çalışmak; teknolojinin amacı ise insanların istek ve ihtiyaçlarını karşılamak için doğal dünyada değişiklikler yapmaktır”, yaşam kalitesini kolaylaştırmaktır (MEB, 2005). 2013 yılında yapılan revizyonda ise dersin adı fen bilimleri olarak değiştirilse de vizyon kapsamında fenin teknoloji ile ilişkisine rastlanmaktadır. 2013 fen bilimleri dersi öğretim programı vizyonu "Tüm öğrencileri fen okuryazarı bireyler olarak yetiştirmek" olarak tanımlanmış, bireylerin "fen bilimlerinin teknoloji toplum-çevre ile olan ilişkisine yönelik anlayışa ve psikomotor becerilere sahip olması" gerektiği öğretim programı amaçları arasında belirtilmiştir (MEB, 2013). Ayrıca bireylerde "Bilimin toplumu ve teknolojiyi, toplum ve teknolojinin de bilimi nasıl etkilediğine ilişkin farkındalık geliştirmek" genel amaçlar arasında belirtilmiştir (MEB, 2013). Fen bilimleri dersinin ve bu dersin yürütücüsü olan fen bilgisi öğretmen adaylarının TPAB yeterliklerini ortaya koymak ve bu yeterliği geliştirmek, bilgi toplumuna nitelikli bireyler yetiştirmek için gereklidir (Timur, 2011).

Fen bilimleri dersinde atom, kimyasal bağlar, DNA, yoğunluk, enerji gibi birçok soyut kavram yer almaktadır. Sınıf düzeyleri yükseldikçe fen bilimleri dersindeki soyut kavramlar ve karmaşık özellikler gösteren konular artmaktadır. Bu soyut kavramların ortaokul grubu öğrencilerinin zihinlerinde yeterince somutlaşmaması sonucu bilgi eksiklikleri ve yanlış kavramalar oluşmaktadır. Bu soyut kavramların öğrencilerin zihinlerinde somutlaşması için öğretmene büyük rol düşmektedir. Soyut kavramların somutlaştırılması aşamasında, öğrencilerin birebir dokunabilmeleri, duyabilmeleri ve görebilmeleri açısından materyaller tercih edilmektedir. Materyallerin geliştirilmesi için öğretmenin içerik bilgisine, pedagojik ve teknolojik bilgiye sahip olması gerekmektedir. Tüm bu bilgi türlerinin birleşimi olan, öğretmen ve öğretmen adaylarının sahip olmaları gereken TPAB'ın, mesleklerini icra edecekleri ileriki süreçte materyallere yansıtılması sonucunda amacına hizmet edeceği düşünülmektedir.

İncelenen literatürde, Meriç (2014) çalışmasında, Graham, Burgoyne, Cantrell, Smith, ve Harris (2009) tarafından geliştirilen, Timur ve Taşar (2011) tarafından Türkçe'ye uyarlanan "teknolojik pedagojik alan bilgisi öz-güven ölçeği (TPABÖGÖ)" ile fen bilgisi öğretmen adaylarının teknolojik, pedagojik, alan bilgilerine (TPAB) ilişkin özgüvenlerini incelemeyi amaçlamıştır.

Akyüz vd., (2014), akıllı tahtayı merkeze alan mikro öğretim uygulamalarının fen bilgisi öğretmen adaylarının TPAB'larına ve akıllı tahta kullanımına yönelik algılarına olan etkisini araştırmıştır. Araştırmasında ölçme aracı olarak "TPAB öz güven ölçeği” ve "akıllı tahta kullanımına yönelik öğrenci algı ölçeği” kullanmıştır.

Timur (2011), TPAB öz güven ölçeği ve bilgisayara yönelik öz yeterlik inancı ölçeğinin uyarlama çalışmasını yaparak bu ölçme araçları ile fen bilgisi öğretmen adaylarının kuvvet ve hareket konusundaki TPAB'larının gelişimini incelemeyi amaçlamıştır.

Canbazoğlu-Bilici (2012), geliştirmiş olduğu TPAB anketi ve üç aşamalı 1s1 ve sicaklık testi, TPAB anketinde yer alan TPAB öz-yeterlik ölçeği, gözlem, görüşme gibi veri toplama araçları ile öğretmenlik uygulaması dersinin ve öğretmen yetiştirme programındaki derslerin fen bilgisi öğretmenlerinin TPAB'larının gelişimi üzerindeki etkilerinin değerlendirilmesini amaçlamıştır. 
Kaya (2010), kavram testi ve mülakat gibi veri toplama araçlarıla fen ve teknoloji öğretmen adaylarının fotosentez ve hücresel solunum konusundaki TPAB'larının araştırılmasını amaçlamıştır.

Kılıç, A. (2011), kavram bilgi testi, kavram haritaları, görüş anketi, ders planı hazırlama metodu, mülakatlar, ders video kayıtları, sınıf içi gözlem ölçeği, gözlem notları gibi veri toplama araçlarıyla fen ve teknoloji (FT) öğretmen adaylarının elektrik akımı kapsamındaki konularda TPAB seviyelerini belirlemek ve FT derslerindeki sınıf içi uygulamalarını araştırmayı amaçlamıştır.

Timur ve Taşar (2011), ülkemiz literatüründe TPAB ile ilgili çalışmaları yetersiz görmeleri ve öğretmenlerin TPAB yeterliğinin araştırılması amacıyla bir anket uyarlama çalışmasının literatürdeki eksikliğe katkı sağlayacağını düşündüklerinden, orijinali Graham, Burgoyne, Cantrell, Smith ve Harris (2009)'e ait olan teknolojik pedagojik alan bilgisi öz güven ölçeğinin (TPABÖGÖ) Türkçe'ye uyarlama çalışmasını yapmışlar, sonuç olarak ölçeğin Türkiye'de de kullanılabileceğini tespit etmişlerdir.

Avcı (2014), kişisel bilgi formu, teknolojik pedagojik alan bilgisi ölçeği, teknolojik pedagojik alan bilgisi öz güven ölçeği ve görüş formu gibi veri toplama araçlarıla, fen bilimleri öğretmenlerinin teknolojik pedagojik alan bilgisi ve teknolojik pedagojik alan bilgisi öz güven düzeylerinin belirlenmesi ve bu düzeylerin çeşitli değişkenlere göre farklılık gösterip göstermediğini incelenmeyi amaçlamıştır.

Fen bilgisi öğretmenleri için Graham, Burgoyne, Cantrell, Smith ve Harris (2009) tarafından geliştirilen teknolojik pedagojik alan bilgisi öz-güven ölçeği ile MaKinster, Boone ve Trautmann (2010) tarafından geliştirilen teknolojik pedagojik alan bilgisi öz-yeterlik inanç ölçeği dışında spesifik TPAB ölçeğine rastlanılmaması ve materyal geliştirme süreçlerindeki $\mathrm{TPAB}$ düzeylerini tespit edecek ölçeğin literatürde yer almaması nedeniyle bu çalışmada ölçek geliştirilmesi amaçlanmıştır.

\section{YÖNTEM}

\section{Araşturma Modeli}

Çalışmada nicel araştırma yöntemlerinden tarama modeli kullanılmıştır. Karasar (2002)'a göre tarama modeli, "geçmişte ya da halen var olan bir durumu, var olduğu şekliyle betimlemeyi amaçlayan araştırma yaklaşımı"dır.

\section{Çalışma Grubu}

Araştırmaya Türkiye'nin 12 ayrı ilinde bulunan 12 devlet üniversitesinin fen bilgisi öğretmenliği programlarının üçüncü ve dördüncü sınıflarında 2015 - 2016 öğretim yılında öğrenim görmekte olan 659 fen bilgisi öğretmen adayı katılmıştır. Araştırmaya katılan öğretmen adayları belirlenirken, lisans eğitimlerinde fizik, kimya, biyoloji gibi fenin temel alan derslerini, öğretim yöntem ve teknikleri, öğretim teknolojileri ve materyal tasarımı gibi temel pedagoji derslerini almış olmasına dikkat edilmiştir. Çalışma grubunun demografik bilgileri Tablo 1'de verilmiştir:

Tablo 1. Çalışma Grubunun Demografik Bilgileri

\begin{tabular}{llll}
\hline Değişken & & Frekans (N) & Yüzde (\%) \\
\hline Cinsiyet & Kız & 519 & 78.8 \\
& Erkek & 140 & 21.2 \\
Sınıf düzeyi & 3. Sınıf & 414 & 62.8 \\
& 4. Sinıf & 245 & 37.2 \\
Toplam & & 659 & 100.0 \\
\hline
\end{tabular}

\section{Ölçek Geliştirme Aşamaları}

Ölçeğin geliştirilmesi aşamasında sırasıyla, literatür taraması, görüşme, madde havuzunun oluşturulması, uzman görüşlerinin alınması, ölçeğin taslak uygulaması, pilot uygulama, ölçeğin geçerlik-güvenirlik çalışmaları gerçekleştirilmiştir.

Çalışmadaki ölçek maddelerini oluşturmak için fen bilimleri ve diğer alanlarda TPAB ile ilgili yapılan tüm araştırmaları incelemek amacıyla literatür taraması yapılmıştır.

Yapılan literatür taramasının ardından, çalışma grubunda olmayan fen bilgisi öğretmen adayları, fen bilgisi eğitimi alanında lisansüstü eğitim görmekte olan bireyler ve TPAB alanında çalışmış olan araştırmacılar ile görüşmeler yapılmıştır.

Görüşme verilerinden yola çıkarak 72 maddelik madde havuzu oluşturulmuştur. Madde havuzu oluşturulurken, faktör analizi sonucu çıkması beklenen AB, PB, TB, PAB, TAB, TPB ve TPAB boyutları göz önünde bulundurularak ortalama olarak aynı sayıda madde yazılmıştır. Maddeler 
yazılırken ölçülmek istenen boyuta ilişkin doğru cevap verildiğine ilişkin tutarlılık sağlamak amacıyla, aynı maddeye ilişkin olumlu ve olumsuz maddeler oluşturulmasına ve maddelerin anlaşılabilir olmasına özen gösterilmiştir. Ölçek, cevaplanması istenilen maddeler için "kesinlikle katılıyorum", "katılıyorum", "kararsızım", "katılmıyorum" ve "kesinlikle katılmıyorum" ifadeleri şeklinde beşli likert tipinde hazırlanmıştır. Öğrencilerin olumlu maddelere verdikleri "kesinlikle katılıyorum" şeklindeki yanıtlara beş puan, "katılıyorum" şeklindeki yanıtlara dört puan, "kararsızım" şeklindeki yanıtlara üç puan, "katılmıyorum" şeklindeki yanıtlara iki puan, "kesinlikle katılmıyorum" şeklindeki yanıtlara bir puan verilmiştir. Değerlendirme aşamasında ise olumsuz maddeler üzerinde bu puanlama ters şekilde yapılmıştır.

Ölçeğin geçerlik çalışması için; kapsam geçerliği ve yap1 geçerliği sınamaları yapılmıştır. Ölçeğin kapsam geçerliğini sağlamak amaciyla ölçeğe ilişkin uzman görüşlerine başvurulmuştur. Ölçek, Türkiye'de bulunan üç ayrı devlet üniversitesinin fen bilgisi eğitimi ABD'de görev yapan altı öğretim üyesi ve bir materyal geliştirme uzmanı ile bir doktora eğitimi alan fen bilgisi öğretmeni tarafindan incelenmiştir. Ölçek, dilbilgisi ve anlaşılabilirliği sağlanması amacıyla MEB'de görev yapmakta olan iki Türkçe öğretmeni tarafindan da incelenmiştir. Uzman görüşleri doğrultusunda yeniden gözden geçirilen ölçekten madde çıkarılmazken ve bazı madde köklerinde değişiklikler yapılmıştır.

Uzman görüşlerinin ardından çalışma grubunda yer almayan üçüncü ve dördüncü sınıfta öğrenim görmekte olan 15 fen bilgisi öğretmen adayına, ölçekte anlaşılmayan bir maddenin olup olmadığını test etmek amacıyla ölçeğin taslak uygulaması yapılmıştır. Bu uygulama sonucu anlaşılmayan maddeler yeniden düzenlenerek ölçeğin son şekli verilmiştir. Ölçeğin cevaplaması için gereken süre taslak uygulama sonucu ortalama 30 olarak belirlenmiştir.

Ardından 12 ayrı devlet üniversitesinin fen bilgisi öğretmenliği bölümünün üçüncü ve dördüncü sınıflarında, 2015-2016 eğitim-öğretim yılında öğrenim görmekte olan 659 öğretmen adayına pilot uygulaması yapılmıştır.

Ölçeğin geçerlik ve güvenirlik çalışmaları için, önce SPSS 18 paket programından yararlanılarak açımlayıcı faktör analizi (AFA), daha sonra LíSREL 8.7 programından yararlanılarak doğrulayıcı faktör analizi (DFA) yapılmıştır. AFA ve DFA aynı çalışma grubunun verileri üzerinde yapılmıştır. Taslağın son şekli verildikten sonra, ölçek 15 öğretmen adayına uygulanarak ölçeğin bir birey için uygulanma süresi belirlenmiştir.

\section{BULGULAR}

Ölçeği geliştirme aşamasında faktör analizinden yararlanılmıştır. Faktör analizi, aynı yapıyı ve niteliği ölçen değişkenleri bir araya toplayarak ölçmeyi az sayıda faktör ile açıklamayı amaçlayan bir istatistiksel tekniktir (Büyüköztürk, 2015). Tabachnick ve Fidell (1989)'a göre faktör analizi, yap1 geçerliğinin incelenmesinde en güçlü yöntemdir ve faktör analizi için en az 200 katılımcıdan elde edilen verinin yeterlidir.

Ölçeği geliştirme aşamasında, ölçeğin kapsam ve yapı geçerliğini test etmek, ölçeğin faktör yapısını belirlemek amacıyla açımlayıcı faktör analizinden yararlanılmıştır. Açımlayıcı faktör analizi, değişkenler arasındaki ilişkilerden hareketle faktör bulmaya yönelik bir işlemdir (Büyüköztürk, 2015). Ölçeğin geliştirileceği bu araştırmada, faktör analizi yapılmak üzere 659 katılımcıdan veriler toplanmıştır. Ölçeğe ilişkin açımlayıcı faktör analizine başlamadan önce, veri yapısının faktörleştirmeye uygunluğu ve toplanan verilerin evreni temsil edip etmeme durumunu incelemek amaciyla KaiserMeyer-Olkin (KMO) ve Bartlett küresellik testi sonuçlarına bakılmıştır (Yıldırım ve Selvi, 2015). Ölçeğin KMO değeri (.94) olarak bulunmuştur. KMO değerinin .70'den büyük olması faktör analizi için mükemmel olarak değerlendirilmesi ve Bartlett küresellik testine bakıldığında $(p<.01)$ elde edilen veriler anlamlı farklılık göstermesi, bu veriler üzerinden faktör analizi yapılabileceği sonucuna varılmıştır (Leech, Barrett ve Morgan, 2005).

$\mathrm{KMO}$ ve Bartlett küresellik testleri ile ölçeğin veriler üzerinden faktör analizine uygunluğu tespit edildikten sonra maddelerin hangi faktörler altında yer aldığı belirlemek amaciyla ölçeğe temel bileşenler analizi (PCA) uygulanmıştır. Özdamar (2002)'a göre faktör analizinin amacı, aralarında ilişki bulunduğu düşünülen çok sayıdaki değiş̧en sayısını azaltmak ve değişkenler arasındaki ilişkilerden yararlanarak bazı yeni yapılar ortaya koymaktır. Ölçeklerde yapı geçerliğinin sağlanması için farklı faktörler altında toplanan maddelerin yüksek iki faktör yükü arasındaki farkın en az (.10) olması ve faktör yük değerinin (.45) ya da daha yüksek olması gerekmektedir; fakat bu sınır değer (.30)'a kadar 
indirilebilir (Büyüköztürk, 2015). 72 maddelik ölçekte bu değerlere uymayan 32 madde ölçekten çıkarılması yoluyla işlemler tekrarlanmış, ölçekte toplamda 40 madde kalmıştır. Maddelerin hangi faktörler altında toplandığı ve maddelerin yük değerleri Tablo 2'de verilmiştir.

Tablo 2. Ölçekte Bulunan Maddelerin Faktörlere Dağılımı ve Döndürülmüş Yük Değerleri

\begin{tabular}{|c|c|c|c|c|c|c|c|c|}
\hline Madde No & Faktör 1 & Faktör 2 & Faktör 3 & Faktör 4 & Faktör 5 & Faktör 6 & Faktör 7 & Faktör 8 \\
\hline M56 & .72 & & & & & & & \\
\hline M58 & .68 & & & & & & & \\
\hline M59 & .67 & & & & & & & \\
\hline M57 & .61 & & & & & & & \\
\hline M55 & .60 & & & & & & & \\
\hline M54 & .48 & & & & & & & \\
\hline M64 & .32 & & & & & & & \\
\hline M2 & & .75 & & & & & & \\
\hline M3 & & .67 & & & & & & \\
\hline M5 & & .66 & & & & & & \\
\hline M6 & & .62 & & & & & & \\
\hline M1 & & .57 & & & & & & \\
\hline M4 & & .54 & & & & & & \\
\hline M46 & & .35 & & & & & & \\
\hline M42 & & & .82 & & & & & \\
\hline M41 & & & .72 & & & & & \\
\hline M43 & & & .70 & & & & & \\
\hline M40 & & & .56 & & & & & \\
\hline M13 & & & & .67 & & & & \\
\hline M12 & & & & .63 & & & & \\
\hline M15 & & & & .63 & & & & \\
\hline M11 & & & & .55 & & & & \\
\hline M18 & & & & .52 & & & & \\
\hline M16 & & & & .50 & & & & \\
\hline M14 & & & & .49 & & & & \\
\hline M17 & & & & .49 & & & & \\
\hline M9 & & & & .34 & & & & \\
\hline M37 & & & & & .86 & & & \\
\hline M39 & & & & & .71 & & & \\
\hline M38 & & & & & .67 & & & \\
\hline M33 & & & & & & .64 & & \\
\hline M30 & & & & & & .53 & & \\
\hline M34 & & & & & & .47 & & \\
\hline M48 & & & & & & .34 & & \\
\hline M49 & & & & & & .33 & & \\
\hline M19 & & & & & & & .55 & \\
\hline M51 & & & & & & & .41 & \\
\hline M62 & & & & & & & .40 & \\
\hline M67 & & & & & & & & .56 \\
\hline M68 & & & & & & & & .40 \\
\hline
\end{tabular}

Faktör analizi sonucunda ölçekteki 40 maddeden, yedisi birinci faktörde, yedisi ikinci faktörde, dördü üçüncü faktörde, dokuzu dördüncü faktörde, üçü beşinci faktörde, beşi altıncı faktörde, üçü yedinci faktörde ve ikisi sekizinci faktör altında toplanmıştır. Bu sekiz faktör fen bilgisi öğretmen adaylarının materyal geliştirme konusunda sahip oldukları TPAB öz-yeterliklerinin alt boyutları olarak adlandırılmıştır. Birinci faktör $\mathrm{TPAB}$, ikinci faktör $\mathrm{TB}$, üçüncü faktör fenin yan dallarına ait $\mathrm{AB}$, dördüncü faktör $\mathrm{PB}$, beşinci faktör fenin temel alanlarına ait $\mathrm{AB}$, altıncı faktör $\mathrm{PAB}$, yedinci faktör $\mathrm{TAB}$ ve sekizinci faktör TPB boyutu olarak adlandırılmıştır. Ölçekte yer alan maddelerin hangi faktör altında toplandığı ve faktörlere ilişkin yük değerleri belirlendikten sonra faktör sayısının kontrol edilmesi aşamasına geçilmiştir. Öz değeri bir alınan faktör analizi sonucunda ölçekteki maddelerin sekiz faktör altında toplandığı belirlenmiş ve scree plot sınaması grafiğgi Şekil 2'de verilmiştir. 


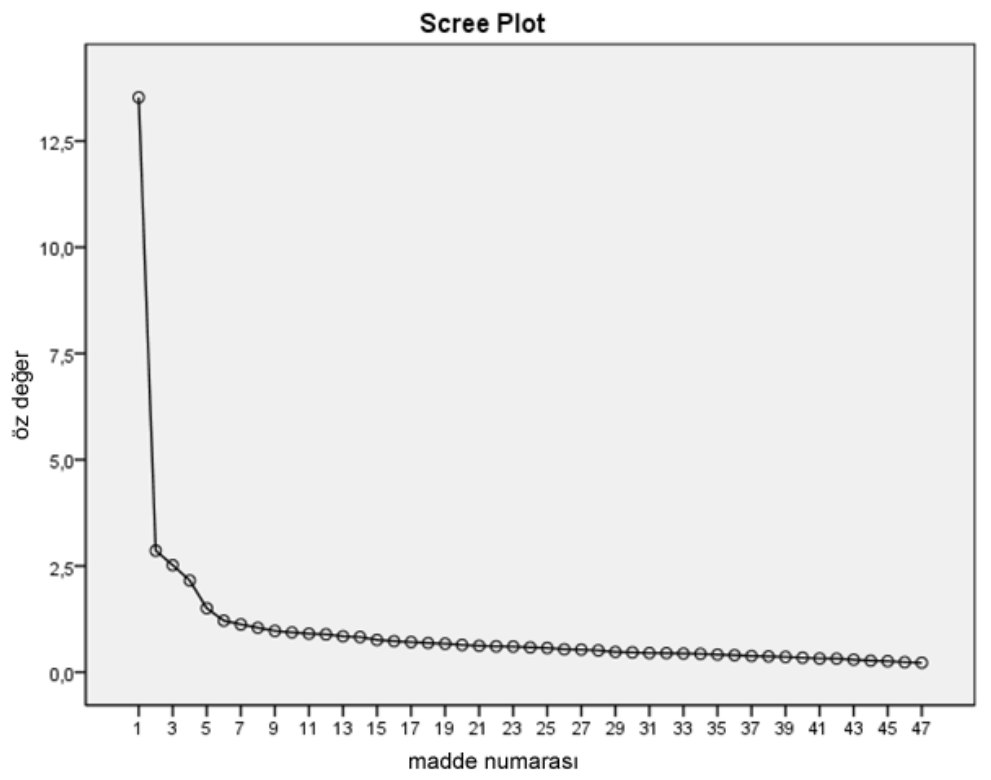

Şekil 2. Ölçeğe ilişkin Scree Plot Grafiğgi.

Ölçekte yer alan sekiz faktöre ait ayrı ayrı ve faktörlerin toplamına ait varyansı Tablo 3'te verilmiştir.

Tablo 3. Ölçeğe ait Faktörlerin Varyanslarının Yüzdesi

\begin{tabular}{cc}
\hline Faktör & Varyansın yüzdesi $(\% \mathrm{~S})$ \\
\hline 1 & 27.62 \\
2 & 4.84 \\
3 & 4.37 \\
4 & 3.52 \\
5 & 2.12 \\
6 & 1.43 \\
7 & 1.36 \\
8 & 1.11 \\
Toplam & 46.37 \\
\hline
\end{tabular}

Ölçekte yer alan sekiz faktör toplam varyansın \%46.37'sini açıklamaktadır. Bunlardan \%27.62'sini birinci faktör, \%4.84'ünü ikinci faktör, \%4.37'sini üçüncü faktör, \%3.52'sini dördüncü faktör, \%2.12'sini beșinci faktör, \%1.43'ünü altıncı faktör, \%1.36'sını yedinci faktör, \%1.11'ini sekizinci faktör oluşturmaktadır. Bir ölçeğin kullanılabilir olması için varyansın \%41'ini açıklaması gerektiğini belirtir (Kline, 1994). Bu ölçeğin tüm faktörlerinin toplam varyansı \%46.37 olduğundan, geliştirilen bu ölçeğin toplam 40 madde ve sekiz faktörlü bir yapı ile kullanılabilir. Ölçeğe ait örnek maddeler ve faktör isimleri Tablo 4'te verilmiştir.

Tablo 4. Maddelerin Faktörlere Göre Dağılımı ve Madde Örnekleri

\begin{tabular}{lll}
\hline Faktörler & Madde Numarası & Örnek Madde \\
\hline TPAB & $\begin{array}{l}54,55,56,57, \\
58,59,64\end{array}$ & $\begin{array}{l}\text { Fen bilimleri dersi öğretim programında yer alan bir konu hakkında, } \\
\text { ögencilerin sahip olduğu kavramsal bilgiyi tespit etmek için } \\
\text { teknolojiyi kullanabilirim. }\end{array}$ \\
\hline TB & $1,2,3,4,5,6,46$ & $\begin{array}{l}\text { Önemli yeni teknolojilere (akıllı tahta, probeware, hesap çizelgeleri } \\
\text { vb.) uyum sağlayabilirim. }\end{array}$ \\
\hline $\begin{array}{l}\text { Fenin Yan } \\
\text { Dallarına Ait AB }\end{array}$ & $40,41,42,43$ & Astronomi ile ilgili temel kavramları açıklayabilirim. \\
\hline PB & $\begin{array}{l}9,11,12,13,14, \\
15,16,17,18\end{array}$ & $\begin{array}{l}\text { Öğrencilerimin konuyu anlama durumlarına göre kullandığım } \\
\text { öğretim yöntemimi değiştirebilirim. }\end{array}$ \\
\hline $\begin{array}{l}\text { Fenin Temel } \\
\text { Dallarına Ait AB }\end{array}$ & $37,38,39$ & Kimya ile ilgili temel kavramları açıklayabilirim. \\
\hline PAB & $30,33,34,48,49$ & $\begin{array}{l}\text { Fen bilimleri dersinde biyoloji konularının kazanımlarına uygun } \\
\text { olarak materyal oluşturabilirim. }\end{array}$ \\
\hline
\end{tabular}




\begin{tabular}{lll}
\hline TAB & $19,51,62$ & $\begin{array}{l}\text { Fen bilimleri dersinde benzeşim programlarını (simulations) } \\
\text { kullanabilirim. }\end{array}$ \\
\hline TPB & 67,68 & $\begin{array}{l}\text { Fen bilimlerini uygulamaya yönelik kullanabileceğim teknolojileri } \\
\text { bilirim. }\end{array}$ \\
\hline
\end{tabular}

Araştırmacı tarafından, açımlayıcı faktör analizi ile belirlenmiş olan ölçeğin faktör yapısının doğrulanmasını test etmek amacıyla doğrulayıcı faktör analizi yapılmıştır. Ölçeğin doğrulayıcı faktör analizi, açımlayıcı faktör analizinin yapıldığı 659 kişilik fen bilgisi öğretmen adayının oluşturduğu örneklemde gerçekleştirilmiştir.

Doğrulayıcı faktör analizi sonuçları, ölçeğin sekiz alt boyutlu bir yapıya sahip olduğunu göstermektedir. Doğrulayıc faktör analizi için $\chi^{2} / \mathrm{df} \leq 3$, NFI $\geq .90, \mathrm{CFI} \geq .95$ ve RMSEA $\leq .08$ değerlerinin olmas1 gerektiği bilinmektedir (Schermelleh-Engel, Moosbrugger ve Müller, 2003). Ölçek için yapılan DFA sonucu $\mathrm{df}=712, \chi^{2}=1755.18(\mathrm{p}=0.00), \chi^{2} / \mathrm{df}=2.47, \mathrm{RMSEA}=.047, \mathrm{NFI}=.96, \mathrm{CFI}=.98$ olarak bulunmuştur. Schermelleh-Engel, Moosbrugger ve Müller (2003)'in DFA sonucunda ölçeğin yapısının kabul edilebilir olması için belirlemiş olduğu değerler referans alındığında, bu ölçeğin yapısının kabul edilebilir olduğu söylenebilir. DAF path (yol) diyagramı Şekil 3'de verilmiştir.

AFA ve DFA'nın yapılmasının ardından güvenirlik çalışmasına geçilmiştir. Ölçeğin güvenirliğini test etmek için iç tutarlılık ile ilgili analizler gerçekleştirilmiştir. Ölçeğin tutarlılık katsayısı Cronbach alpha değeri ve her bir faktöre ilişkin güvenirlik değerleri ayrı ayrı hesaplanmıştır. Bu değerler Tablo 5 'teki gibidir.

Tablo 5. Ölçeğin Her Bir Faktörüne ve Ölçekteki Tüm Maddelere İlişkin Cronbach Alpha Güvenirlik Değerleri

\begin{tabular}{lcc}
\hline Faktör & Madde sayıs & Cronbach alpha değeri \\
\hline 1 (TPAB) & 7 & .88 \\
2 (TB) & 7 & .80 \\
3 (Fenin yan dallarına ait $\mathrm{AB})$ & 4 & .76 \\
4 (PB) & 9 & .85 \\
5 (Fenin temel dallarına ait $\mathrm{AB})$ & 3 & .80 \\
6 (PAB) & 5 & .82 \\
7 (TAB) & 3 & .69 \\
8 (TPB) & 2 & .75 \\
Toplam & 40 & .93 \\
\hline
\end{tabular}

Tablo 5'te de görüldüğü gibi birinci faktörde bulunan yedi maddenin Cronbach alpha güvenirlik değeri (.88), ikinci faktörde bulunan yedi maddenin Cronbach alpha güvenirlik değeri (.80), üçüncü faktörde bulunan dört maddenin Cronbach alpha güvenirlik değeri (.76), dördüncü faktörde bulunan dokuz maddenin Cronbach alpha güvenirlik değeri (.85), beşinci faktörde bulunan üç maddenin Cronbach alpha güvenirlik değeri (.80), altıncı faktörde bulunan beş maddenin Cronbach alpha güvenirlik değeri (.82), yedinci faktörde bulunan üç maddenin Cronbach alpha güvenirlik değeri (.69), sekizinci faktörde bulunan iki maddenin Cronbach alpha güvenirlik değeri (.75) ve ölçekte yer alan 40 maddenin tümüne ilişkin Cronbach alpha güvenirlik değeri (.93) olarak hesaplanmıştır.

Ölçeğin geliştirilmesi aşaması tamamlandıktan ve gerekli istatistiksel analizler yapılıp ölçeğe son hali verildikten sonra 40 maddelik ölçekte olumsuz maddelerin ters çevrilmesi sonucu alınabilecek en düşük puan 40, en yüksek puan ise 200 olarak belirlenmiştir. Geçerlik-güvenirlik çalışmasının ardından yapılan pilot çalışma aşamasında, ölçeğin uygulanması için yeterli olan süre 15 dakika olarak belirlenmiştir. 


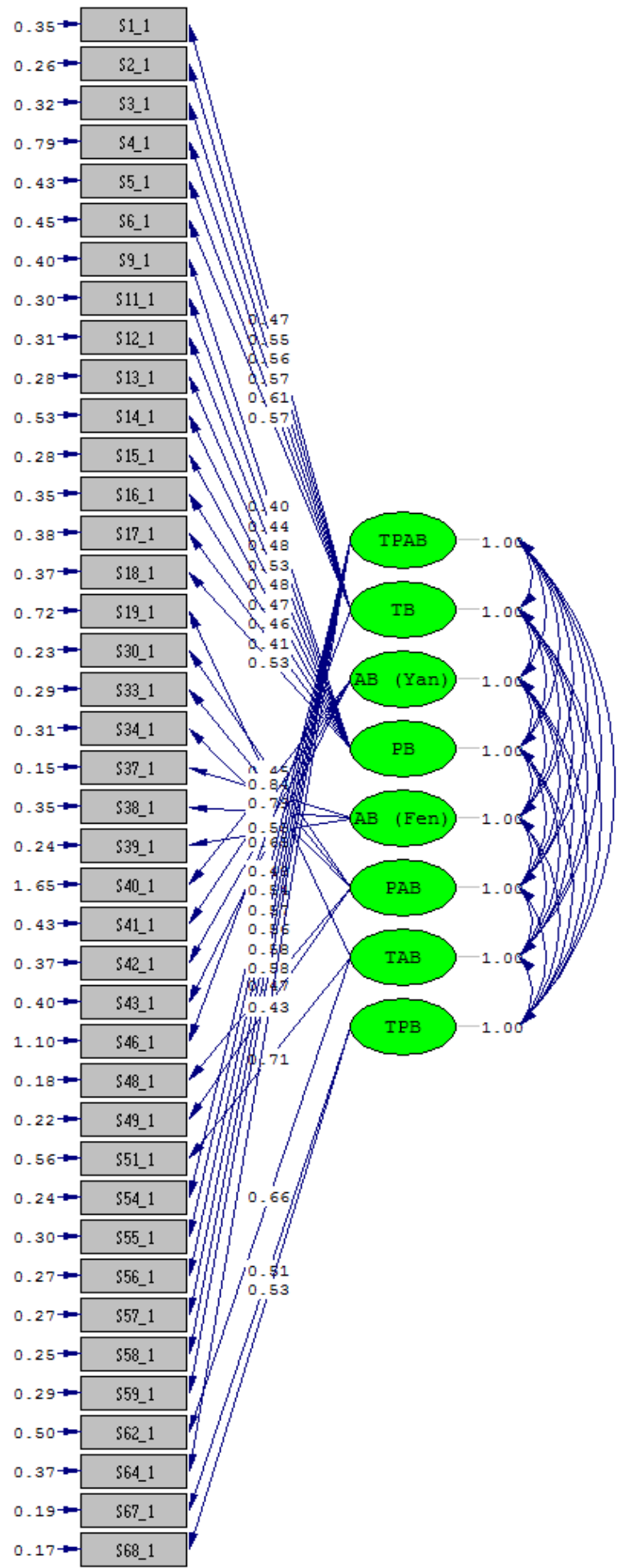

Şekil 3. Fen Bilgisi Öğretmen Adaylarının Materyal Geliştirme Konusunda Sahip Oldukları TPAB Öz-yeterlikleri Ölçeğinin Path (yol) Diyagramı

\section{TARTIŞMA ve SONUÇ}

$\mathrm{Bu}$ çalışmada, fen bilgisi öğretmen adaylarının materyal geliştirme konusunda sahip oldukları TPAB öz-yeterliklerini belirleyen bir ölçek geliştirilmesi amaçlanmıştır. Araştırmacı tarafından geliştirilen bu ölçme aracı için literatür taraması yapılmış, literatür taramasının ardından öğretmen adayları ile görüşmeler yapılmıştır. Görüşmelerin ardından ise ölçekte yer alan 72 madde için uzman görüşü alınmış olup, ölçekten madde çıkarılmayıp bu maddeler üzerinde düzeltmeler yapılmıştır. Taslak yapısının 
oluşturulması sırasında TPAB'ın teorik yapıları esas alınarak, maddeler, ilgili literatür dahilinde yazılmıştır.

Ölçeğe ilişkin KMO değeri (.94) olarak bulunmuştur. KMO değerinin .70'den büyük olması faktör analizi için mükemmel olarak değerlendirilmesi ve Bartlett küresellik testine bakıldığında $(\mathrm{p}<.01)$ elde edilen verilerin anlamlı farklılık göstermesi, bu veriler üzerinden faktör analizi yapılabileceği sonucuna varılmıştır (Leech, Barrett ve Morgan, 2005).

Varimax analizi sonucunda, Tablo 4'te de belirtildiği gibi, ölçeğin TPAB, TB, fenin yan dallarına ait $\mathrm{AB}, \mathrm{PB}$, fenin temel dallarına ait $\mathrm{AB}, \mathrm{PAB}, \mathrm{TAB}$, TPB boyutu olmak üzere sekiz faktörden oluştuğu tespit edilmiştir. Bu sekiz faktör, tüm ölçek puanları içindeki varyansın \% 46.37'sini açıklamaktadır ve ölçeğin yapısını açıklayan varyans, ölçtüğü niteliği yeterince açıkladığı görülmektedir. Ölçeğin yapısının uyum indeskleri incelendiğinde ve Schermelleh-Engel, Moosbrugger ve Müller (2003) referans alındığında ölçek yapısının, bu yönüyle kabul edilebilir uyuma sahip olduğu ortaya çıkmıştır. Ölçeğin güvenirliğinin belirlenmesi için tutarlılık ve kararlılığa yönelik kanıtlar elde edilmiştir. İç tutarlılığa yönelik 40 maddenin tümüne yönelik Cronbach alpha değeri (.93) değerinde çıkmıştır. Ölçekte yer alan faktörlerin her biri ve ölçeğin tamamının Cronbach alpha güvenirlik değeri göz önüne alındığında, bu değerlerin kabul edilebilir güvenirlik değerleri düzeyinde olduğu görülmektedir. $\mathrm{Bu}$ bağlamda da ölçeğin iç tutarlılık düzeyinin yeterli olduğunu görülmektedir.

Ölçeğin geçerlik güvenirlik çalışmaları yapıldıktan sonra sekiz faktörlü, beşli likert tipine sahip, 40 maddelik ölçek elde edilmiş olup Ek-1 de verilmiştir.

Çalışmanın bulguları doğrultusunda araştırma ve uygulamaya yönelik öneriler ise şöyle sıralanabilir:

1)Ölçeğin fen bilgisi öğretmen adaylarına uygulanması ile materyal geliştirme konusundaki TPAB özyeterlik düzeyleri ve hangi düzeyde eksiklikleri olduğu tespit edilerek, verilen eğitim aracılığı ile bu eksiklikler giderilebilir. Bu sayede öğretmen adaylarının ileride derslerinde etkili bir şekilde kullanacakları materyalleri geliştirme becerileri de artırılabilir.

2) Fen bilgisi öğretmenlerinin ve öğretmen adaylarının eksik olduğu boyutları belirlemek amacıyla nitel çalışmalar yürütülebilir.

\section{Yazar Notları}

$\mathrm{Bu}$ çalışma, Yrd. Doç. Dr. Ayşegül ERGÜN danışmanlığında Muhammed Doğukan BALÇIN tarafından hazırlanmış olan "Fen Bilgisi Öğretmen Adaylarının Sahip Oldukları Teknolojik Pedagojik Alan Bilgilerinin (TPAB) Materyal Geliştirme Sürecinde Değerlendirilmesi” isimli yüksek lisans tezinin bir bölümünden oluşturulmuştur.

\section{KAYNAKLAR}

Akyüz, H. İ., Pektaş, M., Kurnaz, M. A., ve Kabataş-Memiş, E. (2014). Akıllı tahta kullanımlı mikro öğretim uygulamalarının fen bilgisi öğretmen adaylarının TPAB'larına ve akıllı tahta kullanıma yönelik algılarına etkisi. Cumhuriyet International Journal of Education, 3 (1), 1-14.

Avc1, T. (2014). Fen bilimleri öğretmenlerinin teknolojik pedagojik alan bilgisi ve öz güven düzeylerinin belirlenmesi. (Yüksek Lisans Tezi), Celal Bayar Üniversitesi, Manisa.

Büyüköztürk, Ş. (2015). Sosyal bilimler için veri analizi el kitabı. Ankara: Pegem Akademi.

Canbazoğlu, S. (2008). Fen bilgisi ögretmen adaylarının maddenin tanecikli yapısı ünitesine ilişkin pedagojik alan bilgilerinin değerlendirilmesi. (Yüksek lisans tezi), Gazi Üniversitesi, Ankara.

Canbazoğlu, S., Demirelli, H., ve Kavak, N. (2010). Fen bilgisi öğretmen adaylarının maddenin tanecikli yapısı ünitesine ait konu alan bilgileri ile pedagojik alan bilgileri arasındaki ilişkinin incelenmesi. Illkögretim Online Dergisi, 9 (1), 275- 291.

Canbazoğlu-Bilici, S. (2012). Fen bilgisi ögretmen adaylarının teknolojik pedagojik alan bilgisi ve özyeterlikleri. (Doktora Tezi), Gazi Üniversitesi, Ankara.

Creswell, J.,W. (2014). Selçuk Beşir Demir (Ed.). Araştırma deseni nitel, nicel ve karma yöntem yaklaşımları. Ankara: Eğiten Kitap Yayıncılık.

Dede, Y., Bayazit, İ., ve Soybaş, D. (2010). Öğretmen adaylarının denklem, fonksiyon ve polinom kavramlarını anlamaları. Kastamonu Ĕ̆itim Dergisi, 18(1), 67-88.

Shulman, L.S. (1986). Those who understand; knowledge growth in teaching. Educational Researcher, 15(2), 414.

Demir, S., ve Bozkurt, A. (2011). İlköğretim matematik öğretmenlerinin teknoloji entegrasyonundaki öğretmen yeterliklerine ilişkin görüşleri. Illkögretim Online, 10(3), 850-860. 
Graham, C. R., Culatta, R., Pratt, M., \& West,R. (2004). Redesigning the teacher education technology course to emphasize integration. Computers in the Schools, 21(1/2), 127-148.

Graham, C. R., Burgoyne, N., Cantrell, P., Smith, L., St. Clair, L., \& Harris, R. (2009). TPACK development in science teaching: Measuring the TPACK confidence of inservice science teachers. TechTrends, 53(5), 7079.

Gömleksiz, M. N., ve Fidan, E. K. (2011). Pedagojik formasyon programı öğrencilerinin web pedagojik içerik bilgisine ilişkin öz-yeterlik alg1 düzeyleri. Turkish Studies. 6(4), 593-620.

Hargrave, C. P., \& Hsu, Y. (2000). Survey of instructional technology courses for preservice teachers. Journal of Technology Teacher Education, 8(4), 303-314.

Harris, J.B., Mishra, P., \& Koehler, M.J. (2007). Teachers' technological pedagogical content knowledge: Curriculum-based technology integration reframed. http://mkoehler.educ.msu.edu/OtherPages/Koehler_Pubs/TECH_BY_DESIGN/AERA_2007/AERA2007 _HarrisMishraKoehler.pdf (28.10.2015 tarihinde indirilmiştir).

Karasar, N. (2002). Bilimsel araştırma yöntemleri. Ankara: Nobel Yayınları.

Kaya, Z. (2010). Fen ve teknoloji ögretmen adaylarının fotosentez ve hücresel solunum konusundaki teknolojik pedagojik alan bilgisinin (TPAB) araştırılması. (Yüksek lisans tezi), Fırat Üniversitesi: Elazığ.

Kılıç, A. (2011). Fen ve teknoloji öğretmen adaylarının elektrik akımı konusundaki teknolojik pedagojik alan bilgilerinin ve sınıf içi uygulamalarının araştırılması. (Yüksek lisans tezi), Fırat Üniversitesi, Elazı̆̆.

Kline, P. (1994). An easy guide to factor analysis. London: Routledge.

Koehler, M. J.,Mishra, P., \& Yahya, K. (2007). Tracing the development of teacher knowledge in a design seminar: Integrating content, pedagogy and technology. Computersand Education, 49(3), 740-762.

Leech, N.L., Barrett, K.C., \& Morgan, G.A. (2005). SPSS for intermediate statistics: Use and interpretation (Second Edition). New Jersey, London: Lawrence Erlbaum Associates, Publishers, Mahwah.

MaKinster, J., Boone,W., \& Trautmann,N. (2010, March). Development of an instrument to assess science teachers' perceived tecnological pedagogical content knowledge. Poster session presented at the 2010 annual conference of the national association for research in science teaching, Philadelphia, PA.

Meriç, G. (2014). Determining science teacher candidates' self-reliance levels with regard to their technological pedagogical content knowledge. Journal of Theory and Practice in Education. 10(2), 352-367.

Milli Eğitim Bakanlığı (MEB). (2005). İlköğretim fen ve teknoloji dersi ögretim programı, Ankara.

Milli Eğitim Bakanlığı (MEB). (2013). İlköğretim kurumları fen bilimleri dersi öğretim programı, Ankara.

Mishra, P., \& Koehler, M. J. (2006). Technological pedagogical content knowledge: A framework for integrating technology in teacher knowledge. Teachers college record,108(6), 1017-1054.

Niess, M. L. (2005). Preparing teachers to teach science and mathematics with technology: Developing a technology pedagogical content knowledge. Teaching and teacher education, 21(5), 509-523.

Niess, M. L. (2011). Investigating TPACK: Knowledge growth in teaching with technology. Journal of Educational Computing Research, 44(3), 299-317.

Özdamar, K. (2002). Paket programlar ile istatistiksel veri analizi. (4. bask1). Eskişehir: Kaan Yayınları.

Pierson, M. E. (1999). Technology practice as a function of pedagogical expertise. (Postgraduate thesis), Arizona State University, Arizona.

Schermelleh-Engel, K., Moosbrugger, H., \& Müller, H. (2003). Evaluating the fit of structural equation models: Tests of significance and descriptive goodness-of-fit measures. Methods of Psychological Research Online, $8(2), 23-74$.

Schmidt, D. A., Baran, E., Thompson, A. D., Mishra, P., Koehler, M. J., \& Shin, T. S. (2009). Technological pedagogical content knowledge (TPACK): The development and validation of an assessment instrument for preservice teachers. Journal of Research on Technology in Education, 42(2), 123-149.

Tabachnick, B. G., \& Fidell, L. S. (1989). Using multivariale statistics. (2nd edition). Cambridge: Harperand Row Publication.

Timur, B., ve Taşar, M. F. (2011). Teknolojik pedagojik alan bilgisi öz güven ölçeğinin (TPABÖGÖ) Türkçe’ye uyarlanmas1. Gaziantep Üniversitesi Sosyal Bilimler Dergisi, 10(2), 839 -856.

Timur, B. (2011). Fen bilgisi ögretmen adaylarının kuvvet ve hareket konusundaki teknolojik pedagojik alan bilgilerinin gelişimi. (Doktora tezi), Gazi Üniversitesi, Ankara.

Türk Eğitim Derneği (TED). (2009). Öğretmen yeterlikleri. Ankara: Adım Okan Matbaacılık.

Uğurlu, R. (2009). Teknolojik pedagojik alan bilgisi çerçevesinde önerilen eğitim programı sürecinde öğretmen adaylarının şekillendirici ölçme ve değerlendirme bilgi ve becerilerinin gelişiminin incelenmesi. (Yüksek lisans tezi), Marmara Üniversitesi, İstanbul.

Yükseköğretim Kurumu (YÖK). (2006). Öğretmen yeterlikleri. Web: http://otmg.meb.gov.tr/belgeler/MEGEP\%20kapsam\%C4\%B1nda\%20MEB\%20ve\%20Y\%C3\%96K\%20 taraf\%C4\%B1ndan\%20belirtilen\%20\%C3\%B6\%C4\%9Fretmen\%20yeterlikleri.doc (29.10.2015 tarihinde alınmıştır). 


\section{EKLER}

Ek 1. Fen Bilgisi Öğretmen Adaylarının Materyal Geliştirme Konusunda Sahip Oldukları TPAB Öz-yeterlikleri Ölçeği

1 Karşılaştığım teknolojik problemleri nasıl çözeceğimi bilirim.

2 Teknolojiyi ve teknolojiyi kullanmayı kolayca öğrenebilirim.

3 Önemli yeni teknolojilere (akıllı tahta, probeware, hesap çizelgeleri vb.) uyum sağlayabilirim.

4 Teknolojik araç-gereçlerle (bilgisayar, projeksiyon cihazı, akıllı tahta vb.) sıcça vakit geçiririm.

5 Birçok farklı teknoloji (bilgisayar, akıllı tahta, projeksiyon cihazı vb.) hakkında bilgiye sahibim.

$6 \quad$ Kullanmam gereken teknolojiyle ilgili yeterli teknik beceriye sahibim.

7 Bilimsel süreç becerilerine sahibim.

$8 \quad$ Sınıfta öğrencilerin performansını nasıl değerlendireceğimi bilirim.

9 Öğrencilerimin konuyu anlama durumlarına göre kullandığım öğretim yöntemimi değiştirebilirim.

10 Öğretim yöntemimi farklı öğrenci seviyelerine göre uyarlayabilirim.

11 Öğrencilerin öğrenmelerini alternatif ölçme araçları (rubrik, portfolyo vb.) ile değerlendirebilirim.

12 Sınıf ortamında çok çeşitli öğretim stratejilerini (sunuş yoluyla öğretim, buluş yoluyla öğretim vb.)

12 kullanabilirim

13 Öğrencilerin genel kavramsal anlamalarını ve kavram yanılgılarını bilirim.

14 Sınıf yönetiminin nasıl organize edilip sürdürüleceğini bilirim.

15 Öğrencilerin fen bilimlerini öğrenme sürecine rehberlik edecek etkili öğretim yöntemlerini (argümantasyon,

15 PDÖ , örnek olay, tartışma vb.) seçebilirim.

16 Fen bilimlerini anlamaya ve anlatmaya yönelik kullanabileceğim teknolojileri (simülasyon, Model-ItTM

6 Virtual Frog, CootiesTM, BIOKids ve WISE) bilirim.

17 Fen bilimleri dersi programı standartlarına uygun materyaller oluşturabilirim.

18 Fen bilimleri dersinde kimya konularının kazanımlarına uygun olarak materyal oluşturabilirim.

19 Fen bilimleri dersinde biyoloji konularının kazanımlarına uygun olarak materyal oluşturabilirim.

20 Kimya ile ilgili temel kavramları açıklayabilirim.

21 Fizik ile ilgili temel kavramları açıklayabilirim.

22 Biyoloji ile ilgili temel kavramları açıklayabilirim.

23 Yer bilimi ile ilgili temel kavramları açıklayabilirim.

24 Astronomi ile ilgili temel kavramları açıklayabilirim.

25 Çevre bilimi ile ilgili temel kavramları açıklayabilirim.

26 Genetik ile ilgili temel kavramları açıklayabilirim.

27 Bilgisayar yazılımı ile ilgili (kurulum programlarının indirilmesi vb. ) teknik problemleri çözebilirim.

28 Derste hangi kavramları öğreteceğime karar verebilirim.

29 Ders sırasında konuya ait öğreteceğim kavramları (genelden özele, basitten karmaşığa) planlayabilirim.

30 Fen öğretimini geliştirebilmek için farklı eğitim yazılımı programlarını (Blackboard, Centra vb. )

30 kullanabilirim.

31 Fen bilimleri dersi öğretim programında yer alan bir konu hakkında, öğrencilerin sahip olduğu kavramsa

31 bilgiyi tespit etmek için teknolojiyi kullanabilirim.

32 Sınıfta dijital teknolojilerle (bilgisayar ve iletişim teknolojileri ile internet, özel amaçlı yazılım programları

32 vb.) bilimsel araştırma-sorgulama yapabilirim.

33 Fen etkinliklerini yapmayı kolaylaştıran dijital teknolojileri (bilgisayar ve iletişim teknolojileri ile internet, özel amaçlı yazılım programları vb.) kullanabilirim.

34 Fen bilimleri dersinde teknolojik araçlarla zenginleştirilmiş bir dersliği etkili olarak kullanabilirim.

35 Öğrencileri fen bilimleri dersine güdüleyebilmek için dijital teknolojileri (bilgisayar ve iletişim teknolojileri

35 ile internet, özel amaçlı yazılım programları vb.) kullanabilirim.

36 Öğrencilerin öğrenme sürecine aktif olarak katılmasını sağlamak amacıyla dijital teknolojileri (bilgisayar ve

36 iletişim teknolojileri ile internet, özel amaçlı yazılım programları vb.) kullanabilirim.

37 Fen bilimleri dersinde benzeşim programlarını (simulations) kullanabilirim.

38 Derslerimde interaktif beyaz tahta (ak1llı tahta) kullanabilirim.

39 Sahip olduğum öğretim yöntemlerini teknoloji ile birlikte sınıf ortamında kullanabilirim.

$\underline{40}$ Fen bilimlerini uygulamaya yönelik kullanabileceğim teknolojileri bilirim. 